RESEARCH ARTICLE

\title{
Anatomical and histological study of the liver and pancreas of two closely related mountain newts Neurergus microspilotus and $N$. kaiseri (Amphibia: Caudata: Salamandridae)
}

\author{
Somaye Vaissi ${ }^{1}$, Paria Parto ${ }^{1}$, Mozafar Sharifi ${ }^{1}$ \\ ${ }^{1}$ Department of Biology, Faculty of Science, Razi University. Baghabrisham 6714967346, Kermanshah, Iran. \\ Corresponding author: Mozafar Sharifi (sharifimozafar2012@gmail.com) \\ http://zoobank.org/72F19481-A9DB-4856-B505-B8136D3ED6B0

\begin{abstract}
Anatomical and histological examinations were conducted on the digestive glands of two closely related mountain newts, Neurergus microspilotus (Nesterov, 1916) and Neurergus kaiseri Schmidt, 1952. In N. microspilotus and N. kaiseri the major digestive glands comprise a very large liver and a small pancreas. In both species the liver has two distinct lobes, right and left. Histologically, the parenchyma of the liver of both species is contained within a thin capsule of fibroconnective tissue. Glycogen deposits and fat storage often dissolve during the routine histological process and produce considerable histological variability. Sinusoids are lined with endothelial cells forming a very thin epithelial sheet, with discontinuous basement membrane. Bile ducts also occur within the parenchyma of the liver. The ducts are lined by simple cuboidal epithelium. The gall bladder is a storage depot for bile. Its mucosa is thrown into numerous folds. The epithelial lining of the tunica muscularis is arranged circularly. There is a lot of pigmentation in the hepatic parenchyma. The pancreas in N. microspilotus and N. kaiseri is roughly triangular in shape, and lies rather to the dorsal side of the duodenum, between it and the stomach. The exocrine portion of the pancreas consists of clusters of pyramidal cells, which are mostly organized in acini. In both species the cells have a dark basophilic cytoplasm, distinct basal nuclei, and many large eosinophilic zymogen granules containing enzymes responsible for the digestion of proteins, carbohydrates, fats and nucleotides.
\end{abstract}

KEY WORDS. Digestive glands, light microscopy, Hematoxylin-Eosin, Periodic acid-Schiff (PAS).

\section{INTRODUCTION}

The digestive system of vertebrates demonstrates various structural and functional adaptations to their diverse feeding habits. The digestive tract also represents a functional link between foraging activity and energy conservation through energy allocation for various activities (Secor 2005, Romão et al. 2011). Over the last decades, field observations and experimental laboratory studies have shown that the anatomy and physiology of the digestive tract of many species are flexible, and can change in response to variation in environmental conditions (McWilliams and Karasov 2001). A variety of glands are present within the digestive tract. The liver and pancreas are major secretory structures that lie across the stomach and duodendum and are derived from the embryonic gut. The liver is the largest of the digestive glands, serving as a nutrient storage organ and producer of bile (Vitt and Caldwell 2009). The bile drains from the liver into the gallbladder and then moves via the bile duct into the duodenum, where it assists in the breakdown of food. The amphibian liver is located posterior and ventral to the heart, and the gross anatomy of the former varies depending on the taxonomic group, but generally conforms to the body shape of the amphibian. Anurans have a bilobate liver, while caudate have a slightly elongated and emarginated liver, and in the caecilians it is slightly emarginated and is very elongated. The gall bladder is intimately associated with the liver in many groups of vertebrates, with a bile duct connecting it to the duodenum. The pancreas is a smaller, diffuse gland. It secretes digestive fluids into the duodenum and also its endocrine portion produces insulin (Vitt and Caldwell 2009).

In Iran, the genus Neurergus has a relatively wide geographic distribution, ranging from the southern Zagros Mountains to the mid-Zagros range, and extending into Iraq and southern Turkey (Baloutch and Kami 1995). Afroosheh et al. (2016) demonstrated that Neurergus microspilotus (Nesterov, 1916) occurs in 42 highland streams in the mid Zagros 
Mountains, at elevations ranging between 630-2057 m.a.s.l. N. microspilotus is listed as a Critically Endangered species by the International Union for Conservation of Nature (IUCN) (Sharifi et al. 2009, IUCN 2011). Neurergus kaiseri Schmidt, 1952 is endemic to first order streams at elevations ranging between 800 and $1500 \mathrm{~m}$ a.s.l., and occurs in 36 highland streams (Mobaraki et al. 2014). N. kaiseri has also been evaluated as being vulnerable species by IUCN criteria (IUCN 2016). This species has also been amended to the Appendix I of the Convention to the International Trade to Endangered Species (CITES). $N$. microspilotus is slightly larger than N. kaiseri and can be found in different climatic regions. Although both species of Neurergus occur in highlands' first order streams, the macro-ecology of these two areas (mid-Zagros and southern Zagros) are distinctively different. In the southern Zagros Range, where N. kaiser, occurs, the climate is warm without freezing temperatures in the winter, while in western Zagros, where $N$. micropilotus occurs, the climate is cold with pronounced seasonal variations, including a prolonged winter freezing. In both areas the mountain newts are top predators of the diverse benthic macro-invertebrates (Sharifi and Assadian 2004).

The main objective of this study is to describe the digestive gland (including the liver and the pancreas) of two critically endangered mountain newts. We compare and contrast the specific similarities and differences in the anatomy and histology of these two digestive organs.

\section{MATERIAL AND METHODS}

Several newts of N. microspilotus and N. kaiseri were collected from Kavat Stream $\left(34^{\circ} 53 \mathrm{~N}, 46^{\circ} 31 \mathrm{E}\right)$ in the mid-Zagros in western Iran, and Bozorgab Stream in the southern Zagros Mountains (32 $56 \mathrm{~N} .48^{\circ} 28 \mathrm{E}$ ) in spring 2012 (April to May), respectively, and were kept captive at a breeding facility (CBF) in the Razi University (Sharifi and Vaissi 2014). Permits for collections for the scientific study of N. microspilotus were issued by the Regional Office of Environment in Kermanshah Province; and for N. kaiseri, from the equivalent office in Khoramabad Province. The newts were maintained in a $75 \times 45 \times 35 \mathrm{~cm}$ glass aquarium, supplied with local water and were fed earthworms or blood worms. Two females and two males of N. microspilotus and $N$. Kaiseri, which died at the CBF, were subjected to the present histological study. All animals were in resting condition and each with a body length of about $173.91 \pm 17.75 \mathrm{~mm}$ for $N$. kaiseri and $192.35 \pm 10.20 \mathrm{~mm}$ for $N$. microspilotus. The body length was measured as the distance from the tip of the snout to the posterior border of the cloacal opening. The body was divided into five parts. The specimens were fixed in $10 \%$ formaldehyde and dehydrated in a series of ethanol treatments, starting from the $70 \%$ storing solution, then were cleared in xylene, embedded in paraffin, and serially sectioned at $7 \mu \mathrm{m}$ with a rotary microtome. The sections were stained with Hematoxylin-Eosin for general morphology and PAS for identifying carbohydrates according to the protocol of Luna (1968). Sections were observed with an Olympus microscope (Leica Galen III) and were photographed with a digital camera (Leica with Dinocapture 2) mounted to a microscope.

\section{RESULTS}

The livers in N. microspilotus and N. kaiseri are similar and have two distinct lobes, right and left. The left lobe is longer than the right, with a sharp distal end, while the distal end of the right lobe is attached to a spine-shaped accessory process on its medial surface. In both species, it lies ventral to the stomach, and, when fresh, is dark red in color. A thin layer of serous membrane with scattered melanin pigment covered the liver. In the two species the liver is an elongate organ with its anterior end attached to the transverse septum, and extending at least as far posteriorly as the duodenum. In every case the major part of the liver lies on the right side of the body cavity, leaving room for the stomach on the left, and the liver completely suspended by mesenteries. There is a gall bladder lying just dorsal to the right lobe of the liver. The main fissure of the liver is long but does not penetrate deep into the liver on its ventral surface. Therefore, the lobs are less evident on this surface than in dorsal section (Figs 1-4).

Analogous in histology, the parenchyma of the liver in $N$. microspilotus and N. kaiseri is contained within a thin capsule of fibroconnective tissue. Thin septa originate from the capsule and divide the liver into incomplete lobules. Hematopoitic tissue is located in the subcapsular region, in multiple layers. The parenchyma itself is primarily composed of polyhedral hepatocytes, typically with central nuclei. Fat storage often dissolved during the routine histological process, and glycogen mass, look like scattered red dots in the cytoplasm and produce considerable histological variability. The histology of the liver of newts differs from that of mammals in that there is a pronounced tendency for the disposition of the hepatocytes in lobules, and the typical portal triads of the mammalian liver are rarely seen. Sinusoids are lined with endothelial cells forming a very thin cytoplasmic sheet. The nuclei of these cells are elongated and protrude into the sinusoidal lumen. The endothelium is fenestrated by small pores. Melanomacrophages can be seen on the sinusoidal wall and also on the hematopoitic component of the liver, and they have melanosyntethic activity. Bile ducts also occur within the parenchyma of the liver. Originating between adjacent hepatocytes, bile canaliculi anastomose to produce the canal of Herring, which has a larger diameter. The ducts are lined by simple cuboidal epithelium (Figs 5-8). Hepatocyte nuclei were round with blue-violet color. The bile drains into the duodenum by the common bile duct. Smaller ducts within the liver are lined with a single layer of cuboidal epithelial cells. The gall bladder is a storage depot for bile. Its mucosa is thrown into numerous folds. The epithelial lining of the bladder is simple columnar and the tunica muscularis is arranged circularly (Figs 9-10). 

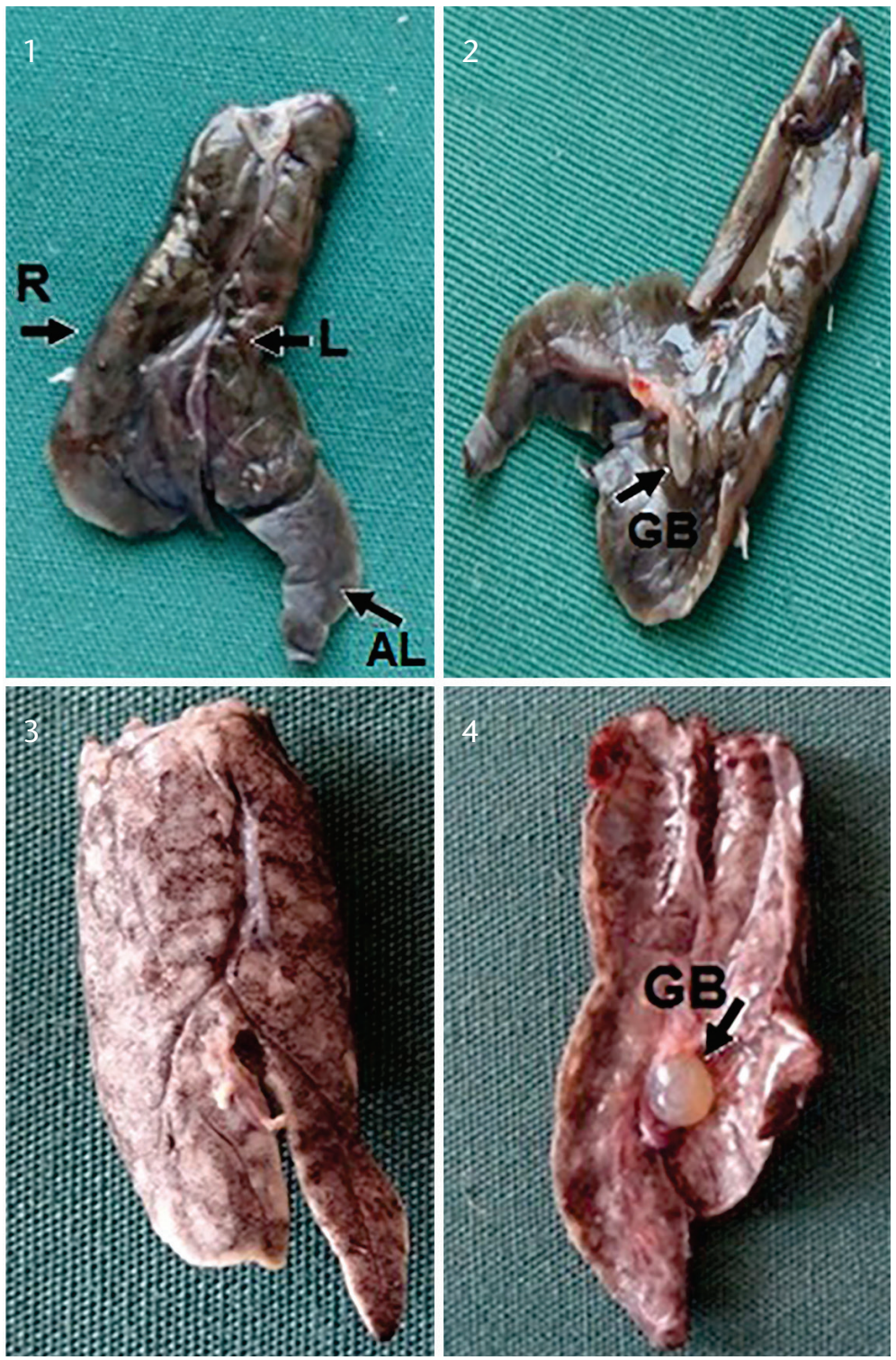

Figures $1-4$. The liver of $N$. microspilotus $(1,2)$ and $N$. kaiseri $(3,4) .(1,3)$ Dorsal surface; $(2-4)$ ventral surface. (R) Right, (L) left, (AL) accessory lobe, (GB) gall bladder.

The pancreas in N. microspilotus and N. kaiseri are similar in appearance and both are roughly oblong glands that lie posterior to the greater curvature of the stomach, and are connected to the duodenum (Figs 11-14). The pancreas is made up of small clusters of glandular epithelial cells. About $1 \%$ of the cells are organized into clusters called pancreatic islets (islets of Langerhans). They form the endocrine portion. The remaining $99 \%$ of the cells are arranged in clusters called acini and constitute the exocrine portion. The exocrine portion of the pancreas consists of clusters of pyramidal cells mostly organized in acini. The cells have a dark basophilic cytoplasm, distinct basal nuclei, and many large apical eosinophilic zymogen granules containing enzymes responsible for the digestion of proteins, carbohydrates, fats and nucleotides, which is called pancreatic juice. Enzymes are delivered into to the duodenum via the pancreatic ductules, which coalesce to form the main pancreatic duct. This latter opens, distinctly or after rejoining the common bile duct, into the duodenum. The pancreatic ductules and the main pancreatic duct are lined with cuboidal to columnar epithelium, respectively (Figs 11-14). 

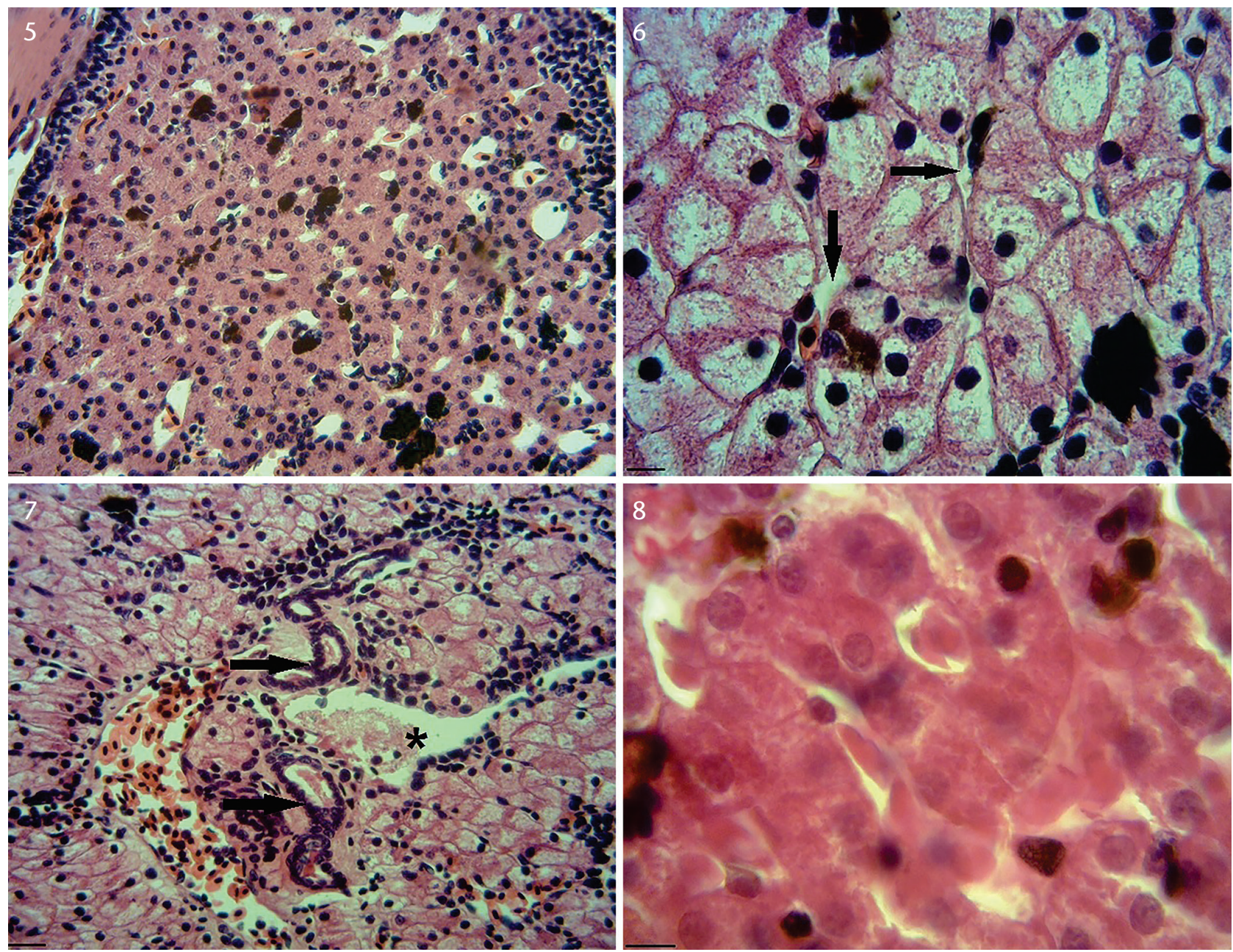

Figures 5-8. Liver of N. microspilotus. (5) The liver tissue demonstrates the sponge-like appearance of the parenchyma, which is composed of polyhedral hepatocyts. Numerous dark brown spots are small melanomacrophage centers (H\&E, $\times 1000)$. (6) Cords of hepatocyte separated by sinusoids (arrows) containing erythrocyte. Hepatocytes are large cells with central nuclei $(H \& E, \times 4000)$. (7) Central vein $(*)$ and intrahepatic ducts (arrow) are seen in this picture (H\&E, $\times 2500)$. (8) Liver parenchyma (PAS, $\times 1000)$. One of the liver's most metabolic functions is storage of glycogen. At this high magnification, one can see that the hepatocytes are strongly stained in magenta by the PAS method; this reaction reveals the presence of red granules including glycogen.

\section{DISCUSSION}

In most amphibian species, the liver is divided into right and left lobes (Grafflin 1966). However, the Taiwanese frog, Hoplobatrachus regulosus (Wiegmann, 1834), and Chinese Fire-bellied Newt, Cynops orientalis (David, 1873), have three and five lobes, respectively (Chen et al. 2003, Xie et al. 2011). In N. microspilotus and N. kaiseri, as well as in Salamandrina Fitzinger, 1826 (Francis 1934, Wonderly 1936), the liver is large, and only very slightly lobed. Neurergus is phylogenetically closer to the $C$. orientalis, they are both in the subfamily Pleurodelinae, so it is unusual that the liver of Neurergus resembles that of Salamandra, which is in another subfamily, Salamandrinae. This should be discussed. However, the hepatic structure normally varies in direct relationship to gender, age, available food (especially with regard to glycogen and fat content), or temperature, and with endocrine influences strongly connected to the environmentally regulated breeding conditions.

The microscopic analysis in N. microspilotus and N. kaiseri revealed that the liver in these species is covered by a thin layer of connective tissue, forming the hepatic capsule, which according to Schaffner (1998), is common to all vertebrates. According to Ross et al. (2003), this capsule contributes to the division of the parenchyma into structural units, called hepatic 

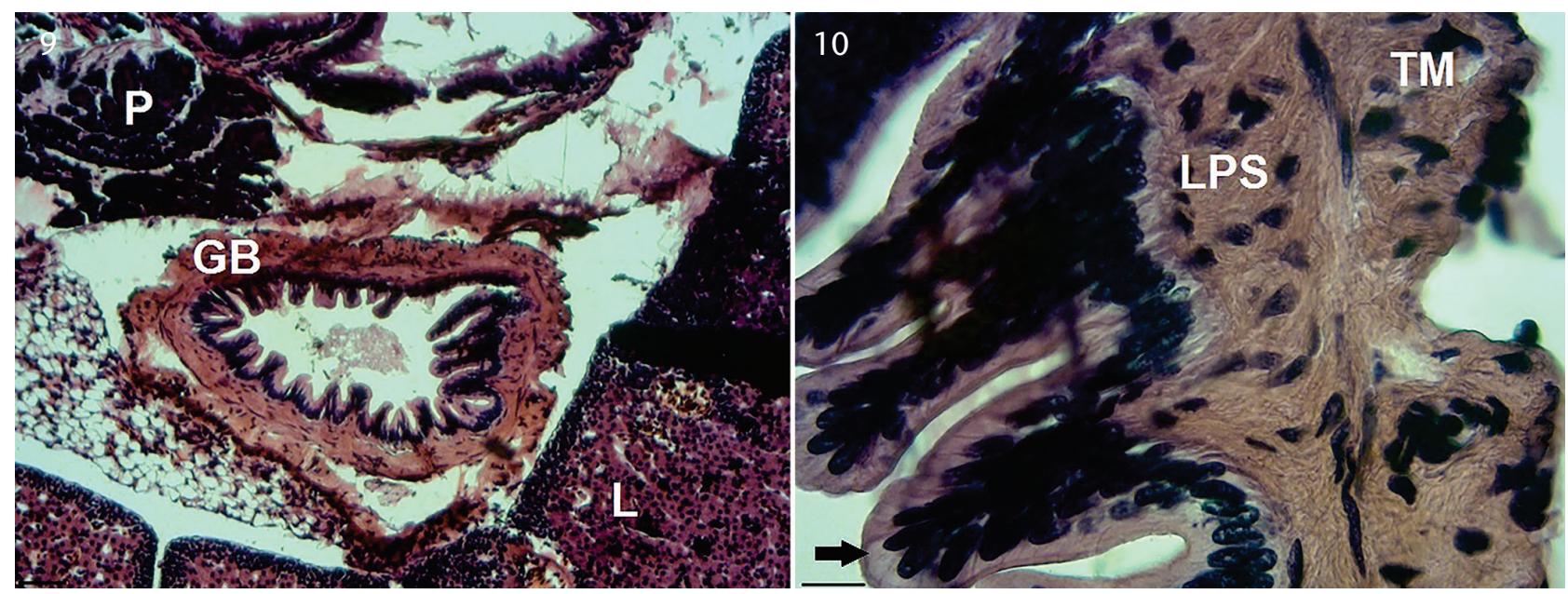

Figures 9-10. (9) Gall bladder of N. microspilotus (H\&E, $\times 300)$. (10) Gall bladder wall consists of a simple columnar epithelium (arrow) supported by underlying fibrovascular lamina propria submucosa (LPS) (H\&E, $\times 2500)$. The epithelial cells are very tall and possess elongated nuclei basally located. These lining cells consecrate bile. (GB) Gall bladder, (P) Pancreas, (TM) Tunica muscularis.

lobules. These are polygonal in shape and are separated by a thin layer of connective tissue, but the trabecules that have a greater quantity of this tissue allow visualization of the interlobular bile ducts, branches of portal vein and of hepatic artery. The central point of the liver is the hilus, through which the portal vein and the liver artery pass. Haar and Hightower (1976) and Xie et al. (2011) described that fine structural characteristics of hepatocytes in the newt Notophthalmus viridescens (Rafinesque, 1820) and C. orientalis included abundant lipid and glycogen inclusions. Melanophores with developing melanosomes are situated throughout the hepatic parenchyma. These results are similar to our observation in N. microspilotus and N. kaiseri.

In the hepatic parenchyma of N. microspilotus and N. kaiseri a large quantity of melanomacrophage centers, as indicated in the Fig. 5, is present. These, also known as macrophage aggregates, are distinctive groupings of pigment-containing cells called melanomacrophages. They are contained in the tissues of amphibians, reptiles and some fish, normally in the liver (Agius and Roberts 2003). According to Frye (1991), these cells are numerous in amphibians and reptiles, except among snakes, in which they are less plentiful (Hack and Helmy 1964). These cells have various functions, among which the synthesis of melanin, fagocytosis and neutralization of free radicals (Guida et al. 2004). The numbers of hepatic melanomacrophages in the amphibian liver are influenced by seasonal variation in some species, and increase with age and with antigenic stimulation in all species (Sichel et al. 2002). In $N$. microspilotus and N. kaiseri there is a gall bladder lying just dorsal to the right lobe of the liver. The gall bladder is a storage depot for bile. Its mucosa is thrown into numerous folds. The epithelial lining of the tunica muscularis is arraigned circularly.

The pancreas contains two distinct populations of cells, the exocrine cells, which secrete enzymes into the digestive tract, and the endocrine cells, which secrete hormones into the bloodstream (Slack 1995). The pancreas arises from the endoderm as a dorsal and a ventral bud, which fuse together to form the single organ. Mammals, birds, reptiles and amphibians have a pancreas with similar histology and mode of development, while in some fish, the islet cells are segregated as Brockmann bodies (Slack 1995). The pancreas in N. microspilotus and N. kaiseri are roughly triangular in shape, and lie rather to the dorsal side of the duodenum, between it and the stomach. In $N$. microspilotus and N. kaiseri the exocrine pancreas is a lobulated, branched, acinar gland. The secretory cells are grouped into acini and are pyramidal in shape, with basal nuclei, regular arrays of rough endoplasmic reticulum, a prominent Golgi complex and numerous secretory (zymogen) granules, containing the digestive enzymes. The lumina of the acini are small and may be terminal or intercalary. At the junction of the acini and ducts are low cuboidal centroacinar cells. The ducts proper are lined with columnar epithelial cells, and in the larger ducts are found small numbers of goblet and brush cells similar to those of the intestine. The acini and smaller ducts are invested with a delicate, loose connective tissue, which becomes more extensive around the larger ducts.

Finally, a number of infectious diseases such as Ranavirosis (Stöhr et al. 2013), Chytridiomycosis (Spitzen-van-der-Sluijs et al. 2011, Bogaerts et al. 2012, Parto et al. 2013, Sharifi et al. 2014), Red leg syndrome (Parto et al. 2014) and Rickettsial inclusions (Vaissi et al. 2017) have been recently reported in specimens belonging to Neurergus, both in the wild and in captivity. Internally, diseases commonly affects the liver and pancreas of amphibian (Bollinger et al. 1999, Green 2001, Wright 2006, Parto et al. 2014). The development and refinement of amphibian medicine remains 

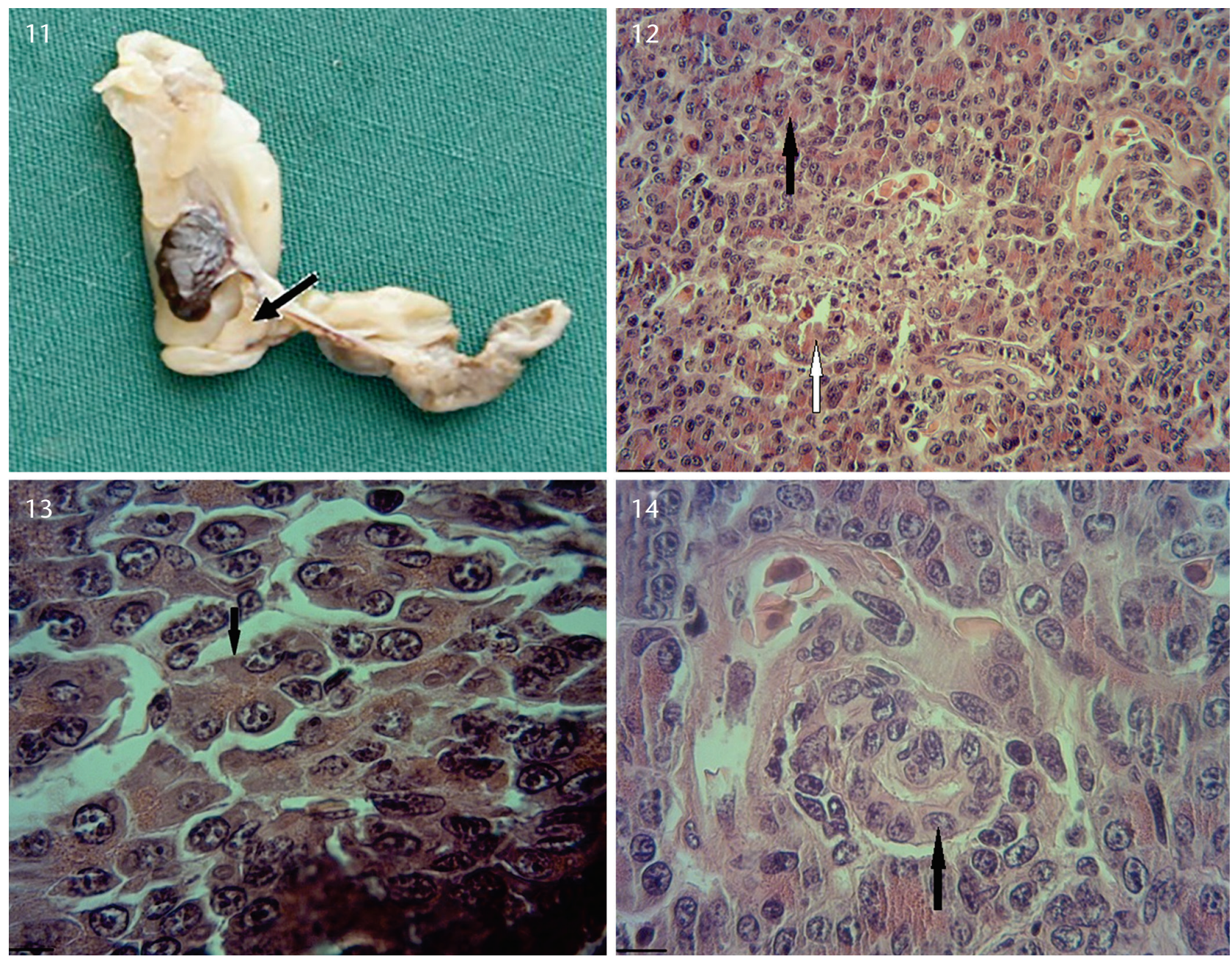

Figures 11-14. Pancreas of N. kaiseri. (11) Pancreas is a triangular organ and it's situated in the curvature of duodenum. (12) Its composed of numerous masses of exocrine acini (black arrow) which secret digestion enzyme. Langerhounse Island (white arrow) is also present $(H \& E, \times 1000)$. (13) Acini (arrow) is enzyme secreting units of exocrine portion of pancreas. Each acinius is an ovoid elliptical cluster of pyramid-shaped secretory cells surrounding the lumen. In the apical portion of the cells these are aggregated bright eosinophilic zymogens granules. The round or flattened cell nuclei are located basally (H\&E, ×4000). (14) Pancreatic acini drain into a branched system of variously sized ducts. In this Image the duct (arrow) is surrounded by a simple cuboidal epithelium (H\&E, $\times 2500)$.

an ongoing practice that reflects the unique life history of these animals and our growing knowledge of amphibian diseases (Densmore and Green 2007). Also, a number of morphological studies that have been conducted might be useful in developing a conservation medicine for the Iranian newts (Sharifi et al. 2013, Parto et al. 2014). The findings of this study demonstrate that the morphological description of the digestive gland of $N$. microspilotus and N. kaiseri are very similar and can be extended to other newts. Results obtained in the current study are important for understanding the digestive processes, underpinning physiological, pathological and phylogenetic studies (Akiyoshi and Inoue 2012), and for the management and conservation, including preventive and therapeutic medicine, of these animals.

\section{LITERATURE CITED}

Afroosheh M, Akmali V, Esmaili S, Sharifi M (2016) Distribution and abundance of the endangered yellow spotted mountain newt Neurergus microspilotus (caudata: salamandridae) in western Iran. Herpetological Conservation and Biology 11: 52-60. 
Agius C, Robert RJ (2003) Melanomacrophage centers and their role in fish pathology. Journal of Fish Diseases 26: 499-509. https://doi.org/10.1046/j.1365-2761.2003.00485.x

Akiyoshi H, Inoue AM (2012) Comparative histological study of hepatic architecture in the three orders amphibian livers. Comparative Hepatology 11: 2. https://doi.org/10.1186/14765926-11-2

Baloutch M, Kami HG (1995) Amphibians of Iran. Tehran University Publications 177: 91-99.

Bogaerts S, Janssen H, Macke J, Schultschik G, Ernst K, Maillet F, Bork C, Pasmans F, Wisniewski P (2012) Conservation biology, husbandry, and captive breeding of the endemic Anatolia newt, Neurergus strauchii Steindachner (1887) (Amphibia: Caudata: Salamandridae). Amphibian and Reptile Conservation 6: 9-29.

Bollinger TK, Mao J, Schock D, Brigham RM, Chinchar VG (1999) Pathology, isolation, and preliminary molecular characterization of a novel iridovirus from tiger salamanders in Saskatchewan. Journal of Wildlife Diseases 35: 413-429. https:// doi.org/10.7589/0090-3558-35.3.413

Chen XQ, Jiang JP, Lin W (2003) Histology of the digestive gland in Hoplobatrachus rugulosus. Journal of Fujian Normal University 19: 117-20.

Densmore CL, Green DE (2007) Diseases of amphibians. ILAR Journal 48: 235-254. https://doi.org/10.1093/ilar.48.3.235

Francis ETB (1934). The anatomy of the salamander. London, Oxford, The Clarendon Press.

Frye FL (1991) Reptile care: An atlas of diseases and treatments. Neptune, TFH Publications, $324 \mathrm{pp}$.

Grafflin AL (1966) In vivo studies of hepatic structure and function in the salamander. The Anatomical Record 115: 53-61. https:// doi.org/10.1002/ar.1091150105

Green DE (2001) Pathology of amphibia. In: Wright KM, Whitaker BR (Eds) Amphibian Medicine and Captive Husbandry. Malabar, Krieger Publishing Company, 401-485.

Guida G, Zanna P, Gallone A, Argenzio E, Cicero R (2004) Melanogenic response of the Kupffer cells of Rana esculenta $\mathrm{L}$. to melanocyte stimulating hormone. Pigment Cell Research 17: 128-134. https://doi.org/10.1046/j.1600-0749.2003. 00118.x

Haar JL, Hightower JA (1976) A light and electron microscopic investigation of the hepatic parenchyma of the adult newt, Notophthalmus viridescens. The Anatomical Record 185: 313-323. https://doi.org/10.1002/ar.1091850305

Hack MH, Helmy FM (1964) Analysis of melanoprotein from Amphiuma liver and from a human liver melanoma. Proceedings of the Society for Experimental Biology and Medicine 116: 348. https://doi.org/10.3181/00379727-116-29244

IUCN (2011) Red list of threatened species. International Union for Conservation of Nature, version 2011.1 http://www.iucnredlist.org [Accessed: June 2013]

IUCN (2016) Neurergus kaiseri. The IUCN Red List of Threatened Species 2016: e.T59450A49436271. http://dx.doi. org/10.2305/IUCN.UK.2016-3.RLTS.T59450A49436271.en. [Accessed: 14 April 2017]
Luna LG (1968) Manual of histologic staining methods of the Armed Forces Institute of the pathology. New York, McGrawHill, $3^{\text {rd }}$ ed.

McWilliams SR, Karasov WH (2001) Phenotypic flexibility in digestive system structure and function in migratory birds and its ecological significance. Comparative biochemistry and physiology. Molecular and Integrative Physiology, Part A, 128: 579-593.

Mobaraki A, Mohsen Amiri M, Alvandi R, Tehrani ME, Kia HZ, Khoshnamvand A, Bali A, Forozanfar E, Browne RK (2014) A conservation reassessment of the Critically Endangered, Lorestan newt Neurergus kaiseri (Schmidt, 1952) in Iran. Amphibian and Reptile Conservation 9: 16-25.

Parto P, Vaissi S, Farasat H, Sharifi M (2013) First report of Chytridiomycosis (Batrachochytrium dendrobatidis) in endangered Neurergus microspilotus in western Iran. Global Veterinaria 11: 547-551.

Parto P, Haghighi ZMS, Vaissi S, Sharifi M (2014) Microbiological and histological examinations in endangered Neurergus kaiseri tissues displaying Red-leg syndrome. Asian Herpetological Research 5: 204-208. https://doi.org/10.3724/ SP.J.1245.2014.00204

Romão MF, Santos ALQ, Lima CF, Desimone SS, Silva JMM, Hirano LQ, Viera LG, Pinto JGS (2011) Anatomical and topographical description of the digestive system of Caiman crocodilus (Linnaeus 1758), Melanosuchus niger (Spix, 1825) and Paleosuchus palpebrosus (Cuvier, 1807). Journal of Morphology 29: 94-99. https://doi. org/10.4067/S0717-95022011000100016

Ross M, Kaye G, Pawlina W (2003) Histology: a text and atlas. Baltimore, Lippincott Williams and Wilkens, $4^{\text {th }}$ ed., $864 \mathrm{p}$.

Schaffner F (1988) The liver. In: Gans C (Ed.) Visceral organs. Philadelphia, Saunders, p. 485-531.

Secor SM (2005) Evolutionary and cellular mechanisms regulating intestinal performance of amphibians and reptiles. Integrative and Comparative Biology 45: 282-294. https://doi. org/10.1093/icb/45.2.282

Sharifi M, Assadian S (2004) Distribution and conservation status of Neurergus microspilotus (Caudata: Salamandridae) in western Iran. Asiatic Herpetological Research 10: 224-229.

Sharifi M, Vaissi S (2014) Captive breeding and trial re-introduction of the endangered yellow spotted mountain newt Neurergus microspilotus (Caudata: Salamandridae) in western Iran. Endangered Species Research 23: 159-166. https://doi. org/10.3354/esr00552

Sharifi M, Bafti S, Papenfuss T, Anderson S, Kuzmin S, Rastegar-Pouyani N (2009) Neurergus microspilotus. In: IUCN (Ed.) Red List of Threatened Species. International Union for Conservation of Nature, version 2012.2, available online at: http:// www.iucnredlist.org [Accessed: 23 April 2015]

Sharifi M, Farasat H, Vaissi S, Parto P, Siavosh Haghighi ZM (2014) Prevalence of the amphibian pathogen Batrachochytrium dendrobatidis in endangered Neurergus microspilotus (Caudata: Salamandridae) in Kavat stream, western Iran. Global Veterinaria 12: 45-52. 
Sharifi M, Naderi B, Hashemi R (2013) Suitability of the photographic identification method as a tool to identify the endangered yellow spotted newt, Neurergus microspilotus (Caudata: Salamandridae). Russian Journal of Herpetology 20: 4-264.

Sichel G, Scalia M, Corsaro C (2002) Amphipia Kupffer cells. Microscopy Research and Technique 57: 477-490. https://doi. org/10.1002/jemt.10101

Slack JMW (1995) Developmental biology of the pancreas. Development 121: 1569-1580.

Spitzen-van-der-Sluijs A, Martel A, Wombwell E, Van Rooij P, Zollinger R, Woeltjes $T$, Rendle $M$, Haesebrouck F, Pasmans F (2011) Clinically healthy amphibians in captive collections and at pet fairs: A reservoir of Batrachochytrium dendrobatidis. Amphibia-Reptilia 32: 419-423. https://doi. org/10.1163/017353711X579830

Stöhr AC, Fleck J, Mutschmann F, Marschang RE (2013) Ranavirus infection in a group of wild-caught Lake Urmia newts Neurergus crocatus imported from Iraq into Germany. Diseases of Aquatic Organisms 103: 185-189. https://doi.org/10.3354/ dao02556

Vaissi S, Parto P, Haghighi ZMS, Sharifi M (2017) Intraerythrocytic rickettsial inclusions in endangered Kaiser's mountain newt, Neurergus kaiseri (Caudata: Salamandridae). Journal of Applied Animal Research 45: 505-507. https://doi.org/10.108 0/09712119.2016.1220385

Vitt LJ, Caldwell JP (2009) Herpetology. New York, Elsevier.
Wonderly DE (1936) A comparative study of the cross anatomy of the digestive system of some North American salamanders. Herpetological Society 4: 31-48. https://doi. org/10.2307/1562578

Wright KM (2006) Overview of amphibian medicine, p. 941-971. In: Mader DR (Ed.) Reptile Medicine and Surgery. St. Louis, Saunders, Elsevier, $2^{\text {nd }}$ ed. https://doi.org/10.1016/B0-72169327-X/50079-1

Xie ZH, Zhong HB, Li HJ, Hou YJ (2011) The structural organization of the liver in the Chinese fire-bellied newt (Cynops orientalis). International Journal of Morphology 29: 1317-1320. https://doi.org/10.4067/S0717-95022011000400041

Submitted: 23 May 2016

Received in revised form: 7 October 2016

Accepted: 19 November 2016

Editorial responsibility: Carolina Arruda Freire

Author Contributions: SV and MSH collected the newts; SV and PP designed the experiments; SV conducted the experiments; SV and PP described the anatomy and histology of the specimens; SV and MSH wrote the paper.

Competing Interests: The authors have declared that no competing interests exist. 